\title{
Canadian Institute of Forestry Policy Statement on the Use of Chemical Pesticides in Forestry - 1983
}

Forests are Canada's most valuable natural resource. They contribute more than any other natural resource to the socio-economic development and wellbeing of the country, and have the potential of contributing in an even greater way to the benefits of succeeding generations of Canadians

Approximately 2 million $\mathrm{km}^{2}$ of a total land area of 5.4 million $\mathrm{km}^{2}$ in Canada is classified as productive forest land. Approximately 150 million $\mathrm{m}^{3}$ of wood was harvested from this productive forest land base in 1981. The total value of shipments from this harvest exceeded $\$ 23$ billion with exports totalling some $\$ 13$ billion, comprising 16 percent of the total exports from Canada and contributing more to the balance of international trade than agriculture, mining, fisheries and fuel combined. In 1980, the forest industry provided direct employment for 310,000 Canadians and indirect employment for another 700,000 - approximately one job in every ten. This same forest also provides the scenic background for a $\$ 3.6$ billion per year outdoor recreation industry; it cleanses and rejuvenates the air we breathe, minimizes erosion, helps to regulate stream flow and water tables, and provides essential habitat for wildlife and fish.

In 1980, the Canadian Council of Resource and Environmental Ministers (CCREM) endorsed a Canadian harvest level target of 210 million $\mathrm{m}^{3}$ by the year 2000 , an increase of $40 \%$ over the 1981 cut. It was estimated that this incremental growth would employ an additional 75000 to 100000 Canadians in the forest industry, would increase lumber and fibre sales by $\$ 22$ billion, and tax revenues by $\$ 1$ billion. To achieve this goal, it was recognized that massive programs of intensive forest management must be undertaken throughout Canada. Among the many problems requiring attention, two are of immediate concern. The first is to satisfactorily re-stock the 26 million hectares of forest land currently understocked or carrying only brush species, and to stop further additions to this backlog. The second is to reduce to acceptable levels, establishment, growth, and mortality losses caused by forest insects, diseases, and competing vegetation, which together are conservatively estimated to reduce forest production by some 100 million $\mathrm{m}^{3}$ annually.

Techniques are currently available to address the two major problems in intensive forest management noted above, but, because they involve the use of chemical pesticides (including herbicides and insecticides) implementation is being severely constrained by political reaction to strong resistance to their use by environmentalist and other public-interest groups. Until continuing research can provide viable alternatives to chemical pesticides, foresters are dependent upon them to achieve many forest management objectives. Without their availability, it is certain that forest production goals set for the year 2000 will not be met; the annual allowable cut from productive forest land will be decreased, and the viability of the forest industry will be substantially reduced. Given this scenario, the contribution of the forest industry to the socio-economic needs of this country will not be sustained or enhanced to the obvious detriment of future generations of Canadians.

The Canadian Institute of Forestry is vitally concerned about this possible future loss in forest productivity and recommends the following policy concerning the use of forest pesticides:

1. The Canadian Institute of Forestry supports the forest harvest level target of 210 million $\mathrm{m}^{3}$ for the year 2000 endorsed by CCREM, and in so doing. supports institution of such intensive forest management practices throughout Canada as will be required to achieve this target.

2. The Canadian Institute of Forestry recognizes that destructive forest insects, diseases and competing vegetation seriously reduce fibre yield of our forests and have detrimental effects on other values such as aesthetics. It realizes that pest management is an important and integral part of intensive forest management, and therefore, supports the use of carefully executed and environmentally conscious pest management practices where these are required to achieve accepted forest production goals.

3. The Canadian Institute of Forestry is aware that chemical pesticides are the major tools available today to reduce the losses caused by forest pests in an effective and economical way. It, therefore, supports responsible use of registered chemical pesticides in forestry practices.
4. The Institute strongly supports continuing and careful monitoring of pesticide use in forestry aimed at detecting and evaluating any adverse environmental and human health effects that might develop through their continued use.

5. The Canadian Institute of Forestry strongly supports continuing, in-depth research on forestry use of pesticides aimed at the development of more effective and environmentally benign pesticides and at technology for their use which will reduce the chances of adverse environmental and human health effects.

6. The Canadian Institute of Forestry strongly encourages and supports continuing research on silvicultural and biological control of forest pests, which will reduce forestry's current reliance on chemical pesticides.

7. The Canadian Institute of Forestry supports existing regulations limiting the application of forest pesticides to licensed applicators.

8. The Institute supports initiatives designed to increase public awareness of pesticide use in forestry and public input into planning processes for the operational use of pesticides in forestry.

9. Because pest management is an important and integral component of intensive forest management, the Canadian Institute of Forestry is supportive of increased activity in pest management training in all undergraduate forestry and technical schools in Canada.

Approved by CIF/IFC Executive Committee $83 / 03 / 30$ 